\title{
Alpins and Thibos vectorial astigmatism analyses - proposal of a linear regression model between methods
}

\author{
Análises vetoriais de Alpins e Thibos para o astigmatismo - \\ proposta de modelo de regressão linear entre os métodos
}

Giuliano de Oliveira Freitas ${ }^{1}$, Joel Edmur Boteon², Mario Jose Carvalho ${ }^{3}$, Rogerio de Melo Costa Pinto ${ }^{4}$

\begin{abstract}
Purpose: To determine linear regression models between Alpins descriptive indices and Thibos astigmatic power vectors (APV), assessing the validity and strength of such correlations. Methods: This case series prospectively assessed 62 eyes of 31 consecutive cataract patients with preoperative corneal astigmatism between 0.75 and 2.50 diopters in both eyes. Patients were randomly assorted among two phacoemulsification groups: one assigned to receive AcrySof ${ }^{\circledR}$ Toric intraocular lens (IOL) in both eyes and another assigned to have AcrySof Natural IOL associated with limbal relaxing incisions, also in both eyes. All patients were reevaluated postoperatively at 6 months, when refractive astigmatism analysis was performed using both Alpins and Thibos methods. The ratio between Thibos postoperative APV and preoperative APV $\left(A P V_{\text {ratio }}\right)$ and its linear regression to Alpins percentage of success of astigmatic surgery, percentage of astigmatism corrected and percentage of astigmatism reduction at the intended axis were assessed. Results: Significant negative correlation between the ratio of post- and preoperative Thibos $A P V_{\text {ratio }}$ and Alpins percentage of success $\left(\%_{\text {success }}\right)$ was found (Spearman's $\left.\rho=-0.93\right)$; linear regression is given by the following equation: $\%_{\text {success }}=\left(-A P V_{\text {ratio }}+1.00\right) x 100$. Conclusion: The linear regression we found between APV ${ }_{\text {ratio }}$ and $\%_{\text {Success }}$ permits a validated mathematical inference concerning the overall success of astigmatic surgery.

Keywords: Phacoemulsification; Astigmatism; Limbus corneae/surgery; Lens implantation, intraocular; Diagnostic techniques,
\end{abstract} ophthalmological.

\section{ReSUMO}

Objetivo: Estabelecer modelos de regressão linear entre os índices propostos por Alpins com os vetores astigmáticos de Thibos, avaliando a validade e a força dessas correlações. Métodos: Série de casos na qual foram avaliados prospectivamente 62 olhos de 31 pacientes de catarata com astigmatismo corneano pré-operatório entre 0,75 e 2,50 dioptrias para ambos os olhos. Os pacientes foram aleatoriamente distribuídos entre 2 grupos: um submetido a implante de lente intraocular (LIO) AcrySof Toric ${ }^{\mathrm{TM}}$ em ambos os olhos e outro grupo, no qual seriam implantadas LIO AcrySof Natural ${ }^{\mathrm{TM}}$ complementada por incisões relaxantes limbares, também em ambos os olhos. Todos os pacientes foram reavaliados aos 6 meses de pós-operatório, sendo feitas análises do astigmatismo refracional tanto pelo método vetorial proposto por Alpins, quanto pelo proposto por Thibos. A razão entre os vetores astigmáticos pós e pré-operatórios de Thibos (VA $\mathrm{pós} / p r e ́)$, bem como a correlação linear com o percentual de sucesso da cirurgia do astigmatismo, o percentual de astigmatismo corrigido e o percentual de redução do astigmatismo no eixo pretendido, propostos por Alpins, foram

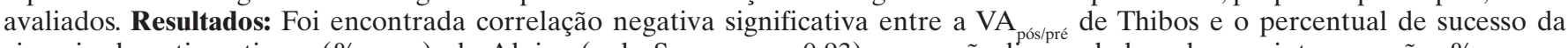
cirurgia do astigmatismo $\left(\%_{\text {Successo }}\right)$, de Alpins $(\rho$ de Spearman $=-0.93)$; regressão linesar dada pela seguinte equação: $\%_{\text {Successo }}=$ $\left(-V A A_{\text {póspré }}+1,00\right) \times 100$. Conclusão: A regressão linear encontrada entre VA póspré e $\%_{\text {Successo }}$ permite uma inferência matemática validada a respeito do sucesso de cirurgia do astigmatismo em termos gerais.

Descritores: Facoemulsificação; Astigmatismo; Limbo da córnea/cirurgia; Implante de lentes intraoculares; Técnicas de diagnóstico oftalmológico

\footnotetext{
${ }^{1}$ Research fellow - Universidade Federal de Minas Gerais (UFMG), Belo Horizonte (MG), Brazil; Staff of Cataract Surgery Department, Instituto de Saúde Ocular - Uberlândia (MG), Brazil;

${ }^{2}$ Ophthalmology professor - Universidade Federal de Minas Gerais (UFMG), Belo Horizonte (MG), Brazil;

${ }^{3}$ Head of Cataract Surgery Department, Instituto de Saúde Ocular, Uberlândia (MG), Brazil;

${ }^{4}$ Biostatistics professor - Universidade Federal de Uberlândia (UFU), Uberlândia (MG), Brazil;

Financial Contributors:

Private: Alcon Labs of Brazil (São Paulo-SP) provided all intraocular lenses, at no cost, for scientific purposes.

Public: Municipal Health Authority of Uberlandia, Uberlândia (MG) funded surgical procedures as regular governmental assistence policy
}

The authors declare no conflicts of interest

Recebido para publicação em 11/3/2013 - Aceito para publicação em 14/6/2013

Rev Bras Oftalmol. 2013; 72 (5): 307-11 


\section{INTRODUCTION}

$\mathbf{V}$ ectors are mathematical expressions that combine values for magnitude and direction. A given vector has specified values for each of these parameters. Astigmatism, with cylinder power and axis (refractive) or magnitude and meridian (corneal), fits such a description ${ }^{(1,2)}$. Manipulation of vectors follows certain rules and can yield resultant vectors from combinations of others. Similarly, the combination of a known preoperative astigmatism and planned surgical effect on that astigmatism can yield desired postoperative astigmatism ${ }^{(1)}$.

The Alpins method is a vectorial analysis that allows determination of the effectiveness of a specific astigmatic treatment. It considers both magnitude and orientation of astigmatism. Three fundamental vectors are used in the analysis: target-induced astigmatism (TIA) - the astigmatic change the surgery was intended to induce, surgically induced astigmatism (SIA) - the astigmatic change the surgery actually induced and difference vector (DV) - the induced astigmatic change that would enable the initial surgery to achieve its intended target. Various relationships between these vectors, such as correction index (SIA/TIA), flattening index ([SIA $x$ Cos $2 \mathrm{x}$ angle between SIA and TIA]/TIA), index of success (DV/TIA) among others, provide a complete description of the astigmatic correction achieved with a specific modality of treatment. It can be determined whether the treatment was on axis, or off axis and whether too much, or too little effect was achieved. The Alpins method has been used by several authors to analyze the astigmatic changes induced with different surgical and nonsurgical options ${ }^{(1)}$, including limbal relaxing incisions ${ }^{(1,3-5)}$, excimer laser refractive surgery, toric intraocular lens implantation, vitrectomy or orthokeratology ${ }^{(6)}$.

If, however, astigmatism is represented in rectangular vector form, conventional scalar methods can be applied to each vector component. Furthermore, standard multivariate statistics can be used to compute population means and variances, define confidence intervals, and test hypotheses. Thibos et al. have proposed such an approach ${ }^{(7,8)}$. According to this method, power vectors are geometrical representations of spherocylindrical refractive errors in three fundamental dioptric components. The first component is a spherical lens with power $M$ equal to the spherical equivalent of the given refractive error $(M=$ sphere + cylinder/2). The remaining two components come from a Jackson crossed cylinder, equivalent to a conventional cylinder of positive power $J$ at axis $\alpha+90^{\circ}$ ( $\alpha=$ the meridian of maximum positive power or angle of astigmatic prescription) $\square$ crossed with a cylinder of negative power $-J$ at axis $90^{\circ}$. Thus, a power vector is that vector drawn from the coordinate origin of this space to the point $\left(M, J_{0}\right.$, $\left.J_{45}\right)^{(7,9)}$. The magnitude of the asigmatic power vector (APV) on the astigmatic plane is defined by $\left(J_{0}^{2}+J_{45}{ }^{2}\right)^{1 / 2}$ and represents a non-signed scalar that may be used to determine statistical differences in the magnitude of astigmatism between two datasets ${ }^{(10,11)}$.

To our knowledge, Alpins and Thibos analyses are not readily interchangeable to one another, when it comes to their mathematical results and interpretation. The aim of the present article is to determine if linear regressions between Alpins indices and Thibos APV are strong enough to be considered clinically relevant.

\section{Methods}

This case series, designed as part of an ongoing Doctorate Thesis of one of the authors (G.F.) at Federal University of Minas Gerais (UFMG), prospectively assessed 31 consecutive cataract patients with preoperative corneal astigmatism between 0.75 and 2.50 diopters (D) in both eyes. Patients were randomly assorted between two phacoemulsification groups: Toric Intraocular Lens (IOL) group, assigned to receive toric intraocular lenses (model AcrySof Toric, Alcon, Inc.) in both eyes and Limbal Relaxing Incisions (LRI) group, assigned to have spherical IOL (AcrySof Natural, Alcon, Inc.) associated with LRI also in both eyes. All patients provided a written informed consent, after they received an explanation of the nature of the study and its potential complications, in accordance to the tenets of Declaration of Helsinki and UFMG's institutional ethics committee protocol. All surgeries were performed between may 2010 and june 2012 at ISO Olhos, Instituto de Saúde Ocular, Uberlândia (MG), Brazil.

Inclusion criteria were age older than 40 years and, for both eyes, visually significant cataract (best corrected visual acuity worse than LogMAR 0.3), regular corneal astigmatism between $0.75 \mathrm{D}$ and $2.50 \mathrm{D}$, pharmacologic mydriasis of at least 6.0 milimeters to allow proper intraoperative visualization of axis marks on the toric IOL.

The following were exclusion criteria: previous surgery in the eye under study, pterygium, ocular disease that would lead to poor postoperative corrected visual acuity (corneal scarring, uveitis, advanced glaucoma, neuroophthalmic disease, significant macular disease or other retinopathy), zonule or pupil abnormalities and any irregular corneal astigmatism.

Preoperatively, every patient had a complete ophthalmic evaluation including $\log$ MAR best corrected distance visual acuity, manifest refraction, slitlamp examination, applanation tonometry, and fundoscopy under pharmacological mydriasys. In addition to corneal topography (Orbscan II, Bausch\&Lomb, Inc.) and ultrasound immersion biometry (OcuScan, Alcon, Inc.). Hoffer $Q$ formula was used in eyes with an axial length shorter than $\leq 22 \mathrm{~mm}$, and SRK/T formula was used for all other cases.

Toric IOL cylinder power and axis placement were determined using the IOL manufacturer's online calculator (www.acrysoftoriccalculator.com). Size and location of LRI were also determined via online application (www.lricalculator.com), according to Donnenfeld's nomogram. For both Toric IOL and LRI groups, biometry, keratometry, main incision location, and surgeon's expected surgically induced astigmatism $(-0.50 \mathrm{D})$ were entered into the calculators, with emmetropia as the goal postoperative refraction, i.e.,zero sphere and the smallest residual cylinder possible.

\section{Surgical technique}

The same surgeon (M.C.) performed all surgeries under mild sedation and topical anesthesia. Just before surgery, a sterile ink pen was used to make two marks on the corneal limbus at the 0 -degree and 180-degree positions with the patient sitting upright at the slitlamp, to avoid ocular torsion.

For both groups, phacoemulsification, followed by IOL implantation, was performed through a $2.75 \mathrm{~mm}$ temporal corneal incision.

In the toric IOL group, the IOL was rotated to align with the planned axis.

For LRI group patients, LRI were created inside the limbus using a calibrated diamond knife with the blade depth set at $600 \mu \mathrm{m}$. 


\section{Postoperative follow-up}

All patients were reevaluated at 6 months postoperatively by an examiner other than the surgeon (G.F.). Postoperative manifest refraction was obtained and analysis of refractive astigmatism, comparing preoperative and postoperative periods, was performed using both Alpins and Thibos methods.

\section{Statistical analysis}

Both Alpins and Thibos calculations were performed using Microsoft Excel ${ }^{\circledR}$ for MacIntosh spreadsheets (version 12.2.7, Microsoft Corp.). Shapiro-Wilk normality tests of data set were performed using IBM SPSS ${ }^{\circledR}$ for Microsoft Windows ${ }^{\circledR}$ software (version 20.0.0). A $p$ value of 0.05 or less was considered statistically significant. The ratio between Thibos 6-month postoperative APV and preoperative APV ( $\left.\mathrm{APV}_{\text {Ratio }}\right)$ and its linear regression with Alpins percentage of success of astigmatic surgery $\left(\%_{\text {Success }}\right)$, percentage of astigmatism corrected $\left(\%_{\text {Corrected }}\right)$ and percentage of astigmatism reduction at the intended axis $\left(\%_{\text {Reduction }}\right)$ were assessed. Pearson's $(r)$ or Spearman's $(\rho)$ linear correlation coefficients, for parametric and non-parametric regressions respectively, were used. Considering each of these coefficients, as modulus, if it was equal to, or less than 0.4 , it was regarded as a weak correlation indicator, if between 0.4 and 0.8 the correlation was considered as moderate and if greater then, or equals to 0.8 , it was indicative of a strong linear correlation evidence ${ }^{(12,13)}$. Bootstrapping (95\% confidence interval) was also taken into account for each non-parametric regression ${ }^{(14)}$.

\section{Results}

The study enrolled 62 eyes of 31 consecutive eligible patients (12 men and 19 women). Patients' mean age was 68.81 years (with a standard deviation of \pm 8.20 years), ranging from 51 to 84 years. None of the eyes required a second intervention. No potentially sight-threatening complications, such as persistent corneal edema, pupillary block, retinal detachment or endophthalmitis were observed.

Data set concerning $\mathrm{APV}_{\text {ratio }}$ and \% success generated from these case series have clearly deviated from normal distribuition, hence Spearman's $\rho$ was used for non-parametric regression analisys.

Thibos and Alpins analises are depicted in tables 1 and 2, respectively, as follows.

The figure 1 depicts a statistically significant negative correlation between $\mathrm{AVP}_{\text {ratio }}$ and \% $\%_{\text {Success }}$ 6-month postoperatively.

We found a Spearman's $\rho$ coefficient for the regression model between $\mathrm{AVP}_{\text {ratio }}$ and \% ${ }_{\text {success }}$ 6-month postoperatively equals to -0.83. Employing bootstrapping calculation, $\rho$ coefficient increased even further to -0.93 . Four eyes deviated remarkably from the trendline. Such eyes were considered as outliers, but they were kept in the study roll.

Spearman's $\rho$ coefficient, even employing bootstrapping, was too low for both $\mathrm{AVP}_{\text {ratio }}$ and $\%_{\text {Corrected }}$ and $\mathrm{AVP}_{\text {ratio }}$ and $\%_{\text {Reduction }}$. Respectively: -0.31 and -0.44 .

\section{DISCUSSION}

Although it provides a sophisticated analysis on astigmatism description and treatment for both refractive and keratometric aspects $^{(1)}$, Alpins method, relies on somewhat complex sequential equations in order to complete its calculations, making its routine
Table 1

Preoperative and 6-month postoperative Thibos APV

\begin{tabular}{lccc}
\hline \multicolumn{2}{c}{ Group } & \\
Diopters & LRI & Toric IOL & p value* \\
\hline $\begin{array}{l}\text { Preoperative } \\
\text { Mean } \pm \text { SD }\end{array}$ & $0.74 \pm 0.30$ & $0.70 \pm 0.37$ & 0.74 \\
$\quad \begin{array}{l}\text { Range } \\
\text { 6-month postoperative }\end{array}$ & 0.25 to 1.38 & 0.13 to 1.38 & - \\
$\quad$ Mean \pm SD & $0.37 \pm 0.13$ & $0.31 \pm 0.09$ & 0.05 \\
Range & 0.13 to 0.63 & 0.13 to 0.50 & - \\
p value & 0.00 & 0.00 & - \\
\hline
\end{tabular}

APV - Thibos astigmatic power vectors; LRI - limbal relaxing incisions; SD - standard deviation; (*) Mann-Whitney U test; $\left(^{\dagger}\right)$ Wilcoxon test preoperative APV x 6-month postoperative APV

Table 2

\section{Six-month postoperative Alpins indices}

\section{Groups}

LRI Toric IOL p value(*)

\begin{tabular}{lccc}
\hline 6-month postoperative IoS & & & \\
Geometric mean $\pm \mathrm{SD}$ & $0.53 \pm 0.25$ & $0.37 \pm 0.24$ & 0.01 \\
Range & 0.31 to 1.42 & 0.03 to 1.14 & - \\
p value & 0.07 & 0.99 & - \\
6-month postoperative FI & & & \\
Geometric mean $\pm \mathrm{SD}$ & $0.62 \pm 0.46$ & $0.81 \pm 0.36$ & 0.00 \\
Range & 0.08 to 1.74 & 0.10 to 1.68 & - \\
p value & 0.43 & 0.44 & - \\
6-month postoperative CI & & & \\
Geometric mean $\pm \mathrm{SD}$ & $0.64 \pm 0.31$ & $0.94 \pm 0.31$ & 0.00 \\
Range & 0.17 to 1.58 & 0.51 to 1.69 & - \\
p value & 0.29 & 0.81 & - \\
\hline
\end{tabular}

CI - Alpins correction index; FI - Alpins flattening index; IoS - Alpins index of success; LRI - limbal relaxing incisions; SD - standard deviation; $(*)$ Mann-Whitney U test; $\left(^{\dagger}\right)$ Wilcoxon test - 1-month postoperative IoS x 6month postoperative IoS

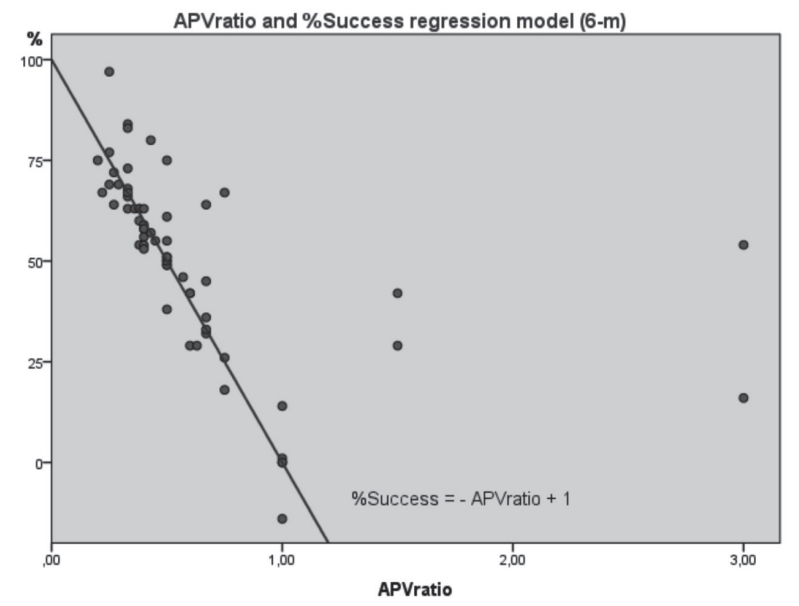

Figure 1: Scatterplot showing a regression model between $A V P_{\text {ratio }}$ and $\%$ success 6 -month postoperatively $\left(\mathrm{APV}_{\text {ratio }}=\right.$ astigmatic power vector ratio, defined as 6-month postoperative astigmatic power vector divided by preoperative astigmatic power vector; $\%_{\text {Success }}=$ percentage of success of astigmatic surgery; $6-\mathrm{m}=6$-month postoperative follow up period). 


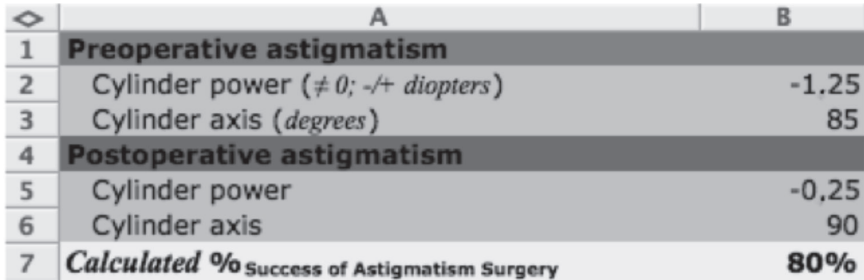

Figure 2: Example of an Excel spreadsheet where the regression formula was set as a function for which inputs of preoperative and postoperative refractive astigmatism render outputs of Alpins $\%_{\text {Success }}$

use often unpractical. Computer softwares designed to perform such calculations in a amenable manner, may be cost prohibitive for many cataract surgeons as a routine tool.

Thibos method on its turn, requires a much simpler design to carry out its calculations, not demanding any specific software to be accomplished. As a drawback, Thibos method offers essencialy a straightforward comparison between preoperative and postoperative refractive power vectors ${ }^{(7,8)}$ fairly related to the success achieved by the astigmatic surgery.

Hence the idea of trying to make these two methods interchangeable, taking advantage of mathematical simplicity from Thibos and the valuable indices from Alpins. To our knowledge, this is the first article, on the literature, to employ both Alpins and Thibos methods to the same patient series, in order to try to correlate their results.

Since both $\mathrm{APV}_{\text {ratio }}$ and $\%_{\text {Success }}$ data deviated from normal distribution ${ }^{(15)}$, non-parametric analises were performed ${ }^{(12)}$.

In statistics, outlier is an observation that is numerically distant from the rest of the data set, clearly deviating from other members of the sample in which it occurs. Occurrence of outliers may be by chance in any distribution, but they are often indicative either of measurement error or a heavy-tailed distribution. Identifying outliers is important both for improving the quality of original data and for reducing the impact of anomalous values in the process of knowledge discovery in databases. Analysis of outliers and their influential points is an important step of the regression analises ${ }^{(16)}$. Since outliers are not generated via any predictable model, any rule for removing outliers, or not, has to be somewhat arbitrary, With such an informal approach, it is impossible to be objective or consistent, or to generalize their elimination process. If the threshold is too strict, some rogue points will remain. If the threshold is not strict enough, too many good points will be eliminated ${ }^{(17)}$. We kept, within our data set, 4 cases presumed as outliers (farthest 4 cases to the right side of the trendline) because Spearman's $\rho$ coefficient, used in our analisys, is not consistently affected by outliers ${ }^{(15,17)}$.

Our findings, summarized in tables 1 and 2, suggest a very strong statistical negative correlation between APV ${ }_{\text {ratio }}$ and $\%_{\text {Success }}(\rho=-0.83$ what implies a negative correlation strength of $83 \%$ and its bootstrapping of 0.93 implies, on its turn, a calculated correlation strength even greater of $93 \%)^{(14)}$. However, correlations between $\mathrm{APV}_{\text {ratio }}$ and $\%_{\text {Corrected }}$ or $\%_{\text {Reduction }}$ cannot be promptly assumed as well. APV ${ }_{\text {ratio }}^{\text {rond }}$ $\%{ }_{\text {Corrected }}$ correlation is only negatively weak $(\rho=-0.31$, what implies a correlation strengh of nearly $31 \%)$. APV ratio and $\%_{\text {Reduction }}$ correlation is moderately waek $(\rho=-0.44$, implying a correlation strengh of $44 \%$ ). For the latter two correlations, statistical significance is irrelevant ${ }^{(12)}$. The rationale behind this

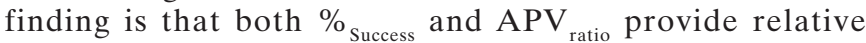
measures of surgical success. It is important to note that both $\%_{\text {Corrected }}$ or $\%_{\text {Reduction }}$ are influenced by any misalignment between intended and actual treatment, such influence is not present on Thibos analisis, hence their weak correlation.

Alpins index of success (IoS) is a suitable parameter for astigmatism treatment assessment ${ }^{(1)}$. Alpins $\%_{\text {Success }}$ is an expression of IoS in percentage terms: $\%_{\text {Success }}=(1-\mathrm{IoS}) \mathrm{x} 100 \%$. APV $V_{\text {ratio }}$ correlates to $\%_{\text {Success }}$, as shown by our model. So, it implies that $A P V_{\text {ratio }}$ also correlates to IoS. In the same manner, APV ratio could be used as a validated alternative assesment tool with more than $90 \%$ certainty. It seems reasonable to us the regression formula we found: $\%_{\text {Success }}=\left(-\mathbf{A P V} \mathbf{V}_{\text {Ratio }} \mathbf{+ 1 . 0 0 )} \mathbf{1 0 0}\right.$ is appropriate for success analysis of an individual surgical case. It may be converted by several softwares to an easy-to-use, unexpensive application with potencial to assist cataract and refractive surgeons an assesment tool of refractive results. Figure 2 shows an example of an Excel spreadsheet where our regression equation was set as a function for which inputs of preoperative and postoperative data render outputs of Alpins $\%_{\text {Success }}$.

Analysis of aggregated cases, such as in comparative studies among techniques might be influenced by the uncertainty inherent to the regression formula, limiting the usage of our formula to individual analyses.

The main limitation of our study is our data set limited to 62 eyes. Larger patient cohorts, specialy if a normal data distribution is present, might further refine our findings, possibly expanding the usage of our formula. The comparison of which technique, toric IOL or LRI, provided better outcomes is beyond the scope of this study, such an analisys is going to be presented in a related study of the same patient series.

In conclusion, linear regression we found between APV and $\%_{\text {Success }}$ permits a validated mathematical inference concerning the overall success of astigmatic surgery for individual patients.

\section{REFERENCES}

1. Alpins NA, Goggin M. Practical astigmatism analysis for refractive outcomes in cataract and refractive surgery. Surv Ophthalmol. 2004;49(1):109-22.

2. Alpins N. Astigmatism analysis by the Alpins method. J Cataract Refract Surg. 2001;27(1):31-49.

3. Carvalho MJ, Suzuki SH, Freitas LL, Branco BC, Schor P, Lima AL. Limbal relaxing incisions to correct corneal astigmatism during phacoemulsification. J Refract Surg. 2007;23(5):499-504. Comment in J Refract Surg. 2008;24(6):562-3.

4. Arraes JC, Cunha F, Arraes TA, Cavalcanti R, Ventura M. Incisões relaxantes limbares durante a cirurgia de catarata: resultados após seguimento de um ano. Arq Bras Oftalmol. 2006;69(3):361-4.

5. Silva EF, Trindade FC. Correção do astigmatismo na cirurgia da catarata. Arq Bras Oftalmol. 2007;70(4):609-14.

6. Alió JL, Piñero DP, Tomás J, Alesón A. Vector analysis of astigmatic changes after cataract surgery with toric intraocular lens implantation. J Cataract Refract Surg. 2011;37(6):1038-49.

7. Thibos LN, Horner D. Power vector analysis of the optical outcome of refractive surgery. J Cataract Refract Surg. 2001;27(1): 80-5. Comment in J Cataract Refract Surg. 2002;28(2):206-7.

8. Thibos LN, Wheeler W, Horner D. Power vectors: an application of Fourier analysis to the description and statistical analysis of refractive error. Optom Vis Sci. 1997;74(6):367-75. Comment in Optom Vis Sci. 1997;74(6):339-41. Optom Vis Sci. 2001;78(1):6-7.

9. Koshy JJ, Nishi Y,Hirnschall N, Crnej A, Gangwani V, Maurino V, et al. Rotational stability of a single-piece toric acrylic intraocular lens. J Cataract Refract Surg. 2010;36(10):1665-70. 
10. Statham M, Apel A, Stephensen D. Comparison of the AcrySof SA60 spherical intraocular lens and the AcrySof Toric SN60T3 intraocular lens outcomes in patients with low amounts of corneal astigmatism. Clin Experiment Ophthalmol. 2009;37(8):775-9. Comment in Clin Experiment Ophthalmol. 2010;38(3):324; author reply 324-5.

11. Mingo-Botín D, Muñoz-Negrete FJ, Won Kim HR, Morcillo-Laiz R, Rebolleda G, Oblanca N. Comparison of toric intraocular lenses and peripheral corneal relaxing incisions to treat astigmatism during cataract surgery. J Cataract Refract Surg. 2010;36(10): 1700-8.

12. Correa SM. Probabilidade e estatística. 2a ed. Belo Horizonte: PUC Minas Virtual; 2003.

13. Shi R, Conrad SA. Correlation and regression analysis. Ann Allergy Asthma Immunol. 2009;103(4 Suppl 1):S35-41.

14. Carpenter J, Bithell J. Bootstrap confidence intervals: when, which, what? A practical guide for medical statisticians. Stat Med. 2000;19(9):1141-64.
15. Razali NM,Wah Y.Power comparisons of Shapiro-Wilk, KolmogorovSmirnov, Lilliefors and Anderson-Darling tests. J Stat Model Analytics. 2011;2(1):21-33.

16. Rahman SM, Sathik MM, Kannan KS. Multiple linear regression models in outlier detection. Int J Res Comp Sci. 2012;2(2):23-8.

17. Motulsky HJ, Brown RE. Detecting outliers when fitting data with nonlinear regression - a new method based on robust nonlinear regression and the false discovery rate. BMC Bioinformatics. 2006;7:123.

\section{Corresponding author:}

Giuliano O. Freitas

ISO Olhos Instituto de Saúde Ocular

R. Eduardo Marquez 50, Martins

ZIP Code 38400-442 - Uberlândia (MG), Brazil

Phone: +55 (34) 3230-5050Fax: + 55 (34) 3230-5055

Email: gofreitas@ufmg.br 